$\infty$

0

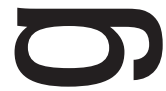

-

ת

1

$\longrightarrow$ 



\title{
ORGANIZAÇ̃̃ES NÃO GOVERNAMENTAIS EM TEMPO REAL: $O$ CASO DAS ONGS/AIDS NO ESTADO DE GOIÁS
}

\author{
NON-GOVERNMENTAL ORGANIZATIONS IN REAL TIME: \\ THE CASE OF NGOS/AIDS IN THE STATE OF GOIÁS
}

\author{
Genésio Amorim Lima - IESA/UFG \\ galj2002@hotmail.com \\ Antonio Carlos Pinheiro - UNIFESP \\ antoniocarlospinheiro@uol.com.br
}

\section{Resumo}

Neste artigo apresentamos uma exposição sobre as 0rganizações Não Governamentais - ONGs, com objetivo de discutir as ONGs/Aids no Estado de Goiás. Para tal, se faz presente uma revisão teórica sobre algumas recentes discussões que permeiam o universo das ONGs e das ONGs/Aids, finalizando com as formas de atuação no Estado de Goiás. As temáticas $0 \mathrm{NG}$, $0 \mathrm{NGs}$ /Aids e Aids direcionam as discussões, que têm como elo o espaço produzido pelas ações sociais institucionais.

Palavras-Chave: ONGs, ONGs/Aids, Aids

\section{Abstract}

This article presents an exhibition about the Non-Governmental Organizations - NGOs, to discuss the NGOs/ Aids in the State of Goiás. For this, a theoretical review is presented about some recent discussions that permeate the universe of NGOs and NGOs/Aids, ending with the forms of action in the State of Goiás. The thematic NGOs, $\mathrm{NGOs/Aids} \mathrm{and} \mathrm{Aids} \mathrm{direct} \mathrm{the} \mathrm{discussions,} \mathrm{which} \mathrm{have}$ as their link the space produced by institutional social actions.

Key-words: NGOs, NGOs/Aids, Aids 



\section{Introdução}

As organizações sociais, genericamente denominadas e reconhecidas de Organizações Não Governamentais - ONGs - são produtos das sociedades contemporâneas. No Brasil, um crescente número de pessoas convive diariamente com este tipo de organização, envolvendo-se de alguma forma, como: voluntário, colaborador, gestor, beneficiário, prestador de serviços, trabalhador remunerado, pesquisador, observador entre outras. Tais organizações não são homogêneas, sendo a heterogeneidade presente em seu universo uma característica das mesmas.

As ONGs se expandem e se direcionam em diversas áreas de atuação: saúde, educação, cultura, lazer, promoção dos direitos humanos, captação de recursos, entre outras, estabelecidas a partir de demandas sociais e da dinâmica das próprias organizações, através de ações político-filantrópicas. Assim, diante da diversidade de organizações sociais que se reconhecem como ONGs, do crescente número dessas organizações e das alterações provocadas por elas na dinâmica político-social na atualidade, da imprecisão do que são tais organizações e qual finalidade se propõem, surgem inúmeros debates e questionamentos.

No Estado de Goiás, acompanhando a trajetória nacional, as ONGs são uma realidade complexa, dividindo-se em diversas áreas de atuação e alterando a dinâmica espacial. Portanto, diante da abrangência de organizações que se reconhecem como não governamentais no Estado, optamos por investigar um grupo específico, ligado pela atuação em uma área comum, da saúde, especificamente relacionado à temática da Aids. Tal escolha se deve à grande quantidade de organizações existentes no Estado que desenvolvem ações políticas e sociais direcionadas a essa doença.

\section{ONGs: da construção de um conceito político ao reconhecimento da legitimidade institucional}

Atualmente, inúmeros são os questionamentos e os debates sobre as ONGs no Brasil. O que são essas organizações? Quais os propósitos, os objetivos e os papéis que se propõem? Tais questões não são novas, sendo simultâneas à própria construção dessas organizações, mas que, diante da dinâmica e complexidade não homogênea manifestada nas práticas das mesmas, das suas múltiplas funções, objetivos e atuações, continuam demandando respostas. 
Portanto, dentre os recentes e numerosos debates sobre as ONGs , optamos em destacar as discussões relacionadas à dimensão conceitual do próprio termo, a partir de sua construção e de sua constante [re]significação, bem como a trajetória conflituosa para alcançar a legitimidade de suas ações, frente à constante e crescente perda de credibilidade por parte da sociedade civil.

Na construção histórica de tais organizações, diversas expressões foram e ainda são associadas ao seu desenvolvimento e crescimento, e que, ao mesmo tempo, contribuíram para a consolidação do fenômeno das ONGs. Cotidianamente, observamos o uso e divulgação de termos como: sociedade civil, sociedade civil organizada, organizações da sociedade civil, organizações sociais, terceiro setor, associações, fundações, organizações sem fins lucrativos entre outras, associadas ao conceito ONG, tornando-o uma expressão usada constantemente de forma generalista para referenciar grande parte destas organizações no Brasil.

De acordo com Manfredi (2002), da Europa ocidental continental vem o predomínio da sigla ONG, cuja origem está na nomenclatura do sistema de representações de organizações das Nações Unidas. Atualmente, é o termo mais utilizado para representar vários tipos organizativos de agentes sociais na atualidade, possuindo inúmeras interpretações.

Autores como Moura (1994) datam o surgimento das ONGs no Brasil desde a época da Colônia. Esta perspectiva de análise refere-se ao trabalho de grupos religiosos caritativos, de difícil comparação com as organizações atuais porque a igreja e o Estado não eram, de fato, separados por lei. Outros autores como Roche (2002) e Gohn (2003) apontam que estas organizações são produtos do século XX, quando o Estado passa a ter papel central na vida das nações, no qual, a partir da segunda metade deste mesmo século, se transformam em um fenômeno mundial.

Ao considerar as ONGs como produtos das sociedades contemporâneas, de acordo com Roche (2002) e Gohn (2003), percebemos que são organizações com um crescente papel na atual sociedade brasileira, e, em alguns casos, configurando-se como extensão do setor governamental. Portanto, na tentativa de conceituá-las, não se pode desconsiderar que são organizações formais, privadas, com fins públicos e sem fins lucrativos, auto-governadas, podendo ou não contar com participação de parte de seus membros como voluntários, com objetivos de realizar mediações de caráter educacional, político, assessoria técnica, prestação de serviços e apoio material e logístico para populações-alvos específicas ou para segmentos da sociedade civil. 
Entretanto, conceituar as ONGs como um movimento organizacional único é uma atitude generalizante. A grande quantidade de organizações, as diferentes áreas de atuações, os diferentes estágios organizativos e a fluidez com que transitam entre o espaço público e o espaço privado contribuem para a uma pluralidade de conceitos que permeiam o universo do denominado Terceiro Setor.

Para além da dimensão conceitual, as ONGs, desde sua origem, na segunda metade do século XX, passam por problemas relacionados à credibilidade que possuem perante a sociedade civil. Porém, a partir da década de 1990, esses problemas se agravaram, decorrentes de constantes críticas e problemas, como: as finalidades que se propõem, as constantes lavagem de dinheiro, desvios de verbas governamentais, projetos infundados, isenção de impostos, entidades pseudobeneficentes etc, que geraram desconfiança quanto à legitimidade dessas organizações.

Apesar da crescente importância das ONGs no país e da tendência cada vez maior do governo de transferir-lhes atribuições, sua posição ainda é bastante ambígua, ora se confundindo como extensão do Estado, ora como extensão de organizações econômicas. A contribuir para a falta de entendimento, têm-se inúmeros equívocos em suas ações. As organizações não são uniformes e adquirem características específicas em cada país, de acordo com leis civis que as regulamentam. $\mathrm{O}$ caminho da legitimidade varia, portanto, de acordo com o país, suas leis internas, seus sistemas de governo e de acordo com a construção de uma cultura das organizações no espaço nacional.

Assim, devido a crescente perda de credibilidade, as ONGs, no início do século XXI, já não podem contar apenas com suas ações para garantir o apoio público. Alcançar legitimidade é um caminho difícil, pois envolve a reputação das entidades, muitas vezes envolvidas com escândalos e fraudes, massivamente divulgados. Paralelamente, as ONGs se pautam em elementos e discursos de interesse comuns às sociedades. Fazem contraponto a uma realidade marcada por uma cultura do privado, do individual, utilizando o voluntariado, a solidariedade e a filantropia como expressões de uma nova cultura que enfatiza "dar" tempo e recursos para o bem dos demais. No Brasil, as ONGs também estão relacionadas às concepções de caridade, filantropia, solidariedade, virtude soberana cristã, fé e esperança etc.

De acordo com a Associação Brasileira de Organizações Não Governamentais - Abong, dados de 2007, as ONGs, atualmente, passam por um processo de redefinições de papéis e de precisão do seu perfil. Em um estudo 
sobre as recentes discussões no campo das organizações sociais no Brasil, essa associação apontou e constatou que o conceito ONG é apenas político, ou seja, ele não existe formalmente e tem sido comumente usado de forma generalista. Existem apenas dois formatos jurídicos no Brasil: associações e fundações. Estes dois formatos podem ter qualificações diferentes enquanto pessoa jurídica e, dependendo da finalidade da organização, podem ser Organização Sem Fins Lucrativos - OSFL, Organização da Sociedade Civil OSCs, ou Organização da Sociedade Civil de Interesse Público - OSCIP. Portanto, o primeiro passo para compreender o conceito ONG é ter fundamental clareza de que não se representa enquanto pessoa jurídica.

A explicitação destas diferenças é importante, uma vez que contribui para a transparência e o conhecimento sobre a diversidade de agentes sociais que atuam na esfera pública e privada, bem como natureza das entidades, formas de organização e o sentido de suas ações. No entanto, a construção de uma legislação para entidades sem fins lucrativos não se limita a questões jurídicas ou formais, envolve a gestão de uma ampla, complexa e contraditória gama de interesses.

Ao mesmo tempo, analisando o histórico de constituição do campo político de grande parte das organizações no Brasil, inicialmente de oposição a um Estado autoritário, cada vez mais as ONGs passaram a ser um elemento essencial na gestão das políticas públicas, não só no exercício do controle e execução social, mas também na realização de parcerias diversas com órgãos públicos, na realização de consultorias, capacitações, estudos, desenvolvimento de projetos pilotos e metodologias inovadoras no campo social. Nesse sentido, a importante concepção ampliada de "público" e de uma esfera pública não-estatal também alimenta uma legitimidade de acesso das organizações da sociedade civil aos fundos públicos.

A recente e crescente parceria entre o setor governamental e o nãogovernamental é mais um elemento de discussão. Tal colaboração, de ação conjunta, redefine novamente o que são as ONGs e quais seus objetivos, estendendo a dimensão do Estado, contribuindo para a perda de rigidez que separam os clássicos setores da economia nacional: primeiro setor [o Estado], o segundo setor [as empresas] e o terceiro setor [as organizações sem fins lucrativos].

Para algumas políticas públicas, por exemplo, como na questão da prevenção e luta contras a Aids, a parceria de governos com ONGs foi e ainda é evidente. No caso das políticas de Aids, as primeiras ações e estratégias de combate à epidemia foram implementadas no âmbito das ONGs forma- 
das por portadores/as do vírus e outros/as militantes da causa, pouco tempo depois do inícioda epidemia no Brasil. Essas ações inovadoras e ilustrativas desenvolvidas na sociedade civil se transformaram, num segundo momento, em políticas públicas. Um outro ponto fundamental neste exemplo, é que as ONGs atuantes nessa temática continuam influenciando e exercendo o controle social sobre a política de Aids no Brasil, independentemente do financiamento que recebem do Estado.

Como se observa, as ONGs são estruturas complexas, parte do universo associativo brasileiro, diversificadas, conflitantes, particulares e ao mesmo tempo articuladas em redes que oferecem inúmeras possibilidades de análise e interpretação pois a temática é inesgotável. Embora seu conceito seja fundamentalmente político, está presente no campo simbólico, de valores. A credibilidade e a legitimidade das ONGs perante a sociedade são elementos importantes para a manutenção das mesmas. As discussões sobre a construção de um marco legal, político e de identidade para estas organizações também permeiam os recentes debates sobre as ONGs. Portanto, para verticalizar a discussão, entraremos agora no campo de organizações específicas quanto à forma de atuação: as denominadas ONGs/Aids.

\section{Organizações em tempo real - o caso das ONGs/Aids}

O surgimento da Aids ${ }^{1}$ está em destaque entre os elementos marcantes do desenvolvimento e evolução das ONGs no Brasil. A multiplicação de organizações baseadas nesta temática ocorreu em escala extraordinária poucos anos após o início da desta epidemia, constituindo-se em um campo político e institucional que passou a ser reconhecido e nomeado posteriormente como ONG/Aids. Estas organizações adquiriram um fundamental papel na construção de políticas nacionais de saúde, redimensionando a atuação de algumas ONGs perante o Estado e sociedade.

Como se sabe, no início da década de 1980 começam a divulgação das primeiras matérias na imprensa brasileira sobre a Aids. Também faz parte desse momento inicial a introdução de noções discriminatórias pela mídia - como as de grupos de risco ou a de promiscuidade, logo alvos de protestos por parte de movimentos sociais que, por outro lado, compreenderam, desde o início, a importância da comunicação e do apelo direto à sociedade. Assim, entre 1985 e 1989, inicia-se o processo de construção das organizações específicas à Aids, que se multiplicam nos anos seguintes: Grupo de Apoio 
e Prevenção à Aids - GAPA, Associação Brasileira Interdisciplinar de Aids Abia e o Grupo Valorização, Integração e Dignidade do Doente de Aids - Pela Vidda [primeira organização de pessoas convivendo com HIV/Aids].

Assim, constituiu-se nesse momento um campo político e institucional que passou a ser nomeado de ONGs/Aids. Teórica e historicamente, a delimitação desse campo foi polêmica. Alguns ativistas militantes passaram a considerar que deste segmento faziam parte apenas as organizações dedicadas ao ativismo contra a Aids e criadas para este fim. Outros consideraram ONGs/Aids todas as organizações que exerciam alguma atividade no campo de luta contra e epidemia, incluindo os grupos feministas, homossexuais, religiosos, educacionais, e ainda entidades cuja existência passou a ser estimulada pela militância contra a Aids, como os grupos de profissionais do sexo ou de usuários de drogas. Outros incluíram ainda nesse campo, mas com uma identidade diferenciada, as casas de apoio, instituições que se tornaram emblemáticas das instituições e ações de solidariedade.

O pluralismo e a diversidade trazidos pelos movimentos sociais marcaram o espaço no qual surge a problemática da Aids, que gradativamente constituiu-se em um movimento social próprio. Em geral, as ONGs eram [e muitas ainda os são] grupos intermediários entre os movimentos de base e o Estado. No caso da Aids, os grupos organizados se constituem identificandose como ONG, mas, paralelamente, possuem uma expressão reivindicativa, de movimento. Assim, as ONGs/Aids surgiram como resultado de múltiplas relações. O parâmetro de referência dessas organizações são exatamente as outras ONGs existentes. As ONGs/Aids se aproximaram das outras pela própria conjuntura política e, ao mesmo tempo, estabeleceram uma diferenciação fundamentada em uma certa especificidade temática - a intervenção e atuação política. A dinâmica política de uma ONG/Aids é completamente diferente das outras ONGs, em que a doença, a sexualidade e a morte não estão presentes. Estes três elementos foram e são fundamentais na construção de uma identidade organizacional para as ONGs/Aids.

No campo de atuação das ONGs, a problemática da Aids introduz peculiaridades. As ONGs/Aids, de acordo com Silva (1998), são atores sociais que reconstroem as formas de atuação política, pois possuem perfis caracterizados pela especificidade da doença, constituindo-se, como movimento social, com trajetória política própria, consolidando seu campo de atuação. As ONGs/Aids foram e são também construídas como resposta aos preconceitos e discriminações gerados e contra uma onda de pânico que marcou o surgimento da epidemia. 
O caráter de urgência impulsionou o surgimento das ONGs/Aids. Segundo Ramos (2004), entre os discursos da época estava o de que a Aids tornava-se um problema de todos e de que seriam necessárias respostas imediatas. A trajetória individual entre a descoberta da soropositividade, o adoecimento e a morte também era rápida, seja pelos limites da medicina da época, seja pelo silêncio das pessoas que incorporam a culpa pela sua soropositividade, muitas vezes associada à orientação sexual.

O tempo individual impulsionou e dimensionou o tempo coletivo no cotidiano das ONGs/Aids. Exatamente por isso, elas não podem ser entendidas na mesma lógica daquelas que atuam frente às questões ecológicas ou em defesa dos movimentos rurais, por exemplo, até porque as ONGs/Aids não atendem especificamente a nenhum movimento social, pois criaram um movimento próprio, em alguns casos se originando do próprio movimento, e que por vezes possuem intersecções quanto ao que as caracteriza como instituições e, simultaneamente, como movimento.

Assim, uma das características das ONG/Aids que, conseqüentemente, minimiza as fronteiras entre o público e o privado, é o fato de ela ser organizada e mantida pelas pessoas diretamente atingidas pela epidemia, em grande parte dos casos, gerando novas formas de atuação política e apresentando a vida privada na criação e sensibilização coletiva. Independente da sorologia dos ativistas, a luta em defesa das pessoas vivendo com HIV e Aids é um princípio que organiza o coletivo e que, portanto, deve ser considerado. Na esfera política, as ONGs/Aids criaram matrizes de solidariedade que surgiram independente do Estado, além do Estado e com o Estado, oferecendo respostas alternativas aos preconceitos e às discriminações, contribuindo para reforçar a auto-estima das pessoas. Segundo Silva (1998):

(...) as ONGs/Aids vêm construindo uma certa identidade que flutua e por vezes é ambígua, entre o que tem sido caracterizado como ONG e como movimento social. São ONGs quando a menção é feita a cada grupo em separado, mas nos encontros nacionais configura-se, e é denominado como tal, um movimento social peculiar, registrado no Boletim Abia (Abia, 1989:1) como "uma militância radical pela vida”. Para Novaes (1994:8), as ONGs/Aids são grupos de interesse e pressão que combinam características de entidades de apoio e serviço com características de movimentos sociais substituindo entidades representativas. (p. 136)

Mesmo assim, embora tenham as ONGs/Aids construído um importante papel no combate à epidemia, não se pode desconsiderar o fato de 
serem organizações autônomas, ainda com pouca fiscalização por parte do setor governamental, assim como grande parte das organizações sem fins lucrativos no Brasil. Ademais, essas organizações também passam por problemas relacionados à legitimidade e credibilidade de suas ações. Isso implica que as ONGs/Aids não estão imunes a críticas, pois precisam apresentar-se de forma ética e transparente, principalmente devido à Aids, transformando-a em uma das principais temáticas de financiamento e fomento.

Devido a peculiar trajetória histórica, as ONGs/Aids brasileiras constituem-se em um movimento com características específicas. Dentre elas, a articulação de ONGs, movimentos, lideranças políticas e governamentais em dois encontros nacionais - o Encontro Nacional de ONGs/ Aids, ENONG e o Encontro Nacional de Pessoas Vivendo com HIV e Aids. Os Encontros Nacionais, além das denominadas ONGs/Aids, contam ainda com a participação de representantes de grupos homossexuais e de lésbicas, feministas, grupos que trabalham com crianças na rua, travestis, dentre outros. A participação dos profissionais de saúde, dos sistemas públicos e privados, é também um dado a ser registrado, seja na exposição de trabalhos ou na convivência dos Encontros, como é o caso dos Programas oficiais: nacional, estaduais e municipais de Doenças Sexualmente Transmissíveis e Aids.

Os Fóruns de ONGs/Aids abrangem todas as unidades da Federação brasileira. Amplo, plural e estruturado em fortes redes de comunicação e articulação político-social, esses fóruns possibilitaram a construção de espaços de solidariedade, luta e ação política, em âmbito nacional. Trata-se de espaços políticos, extremamente complexos, paralelos ao governamental, com autonomia, voltado para as questões de saúde, vida, morte, dignidade, apoio e prevenção relacionados à Aids. No Estado de Goiás, o movimento estadual de luta contra Aids também encontra-se organizado e articulado como Fórum estadual, criado em 2001.

\section{Fórum de ONGs/Aids do Estado de Goiás}

A história das ONGs/Aids em Goiás está relacionada à luta coletiva na prevenção, no debate político, apoio e assistência ao portador HIV/ Aids, acompanhando a trajetória nacional. Grande parte dessas organiza- 
ções construiu-se no início da epidemia na capital Goiânia, porém, desde a década de 1990, cresce o número de organizações no interior do Estado, devido o aumento consideravelmente dos casos de Aids. Essas organizações são, em sua maioria, anteriores a criação do Fórum estadual de ONGs/ Aids.

O espaço de atuação dessas organizações é amplo. O Fórum é uma articulação estadual, constituída por vários tipos de associações. Trata-se de uma associação civil, sem fins lucrativos, fundada em agosto de 2001. Tem como objetivo a articulação estadual de ONGs que atuam no âmbito da pandemia de Aids, sem distinções religiosas, raciais, ideológicas, de gênero, orientação sexual ou partidária, criado a partir das redes estabelecidas pelas ONGs/Aids do restante do país, constituindo-se em importante espaço político-social, articulados por meio de redes de solidariedade, de valores religiosos e pela sensibilização cidadã.

Atualmente é constituído por 26 organizações, engajadas pela luta contra a epidemia de HIV/Aids, incentivando intercâmbio e interação entre as Associações e Movimentos Aids no Estado de Goiás. Tem como finalidades: coordenar um trabalho conjunto de estruturação, fiscalização, manutenção e desenvolvimento das políticas de DSTs/Aids; fazer o controle social e manter diálogo com os órgãos públicos municipais, estaduais, federais e fundações internacionais, assim como outros Fóruns congêneres, propondo ações conjuntas; incentivar e co-promover campanhas de prevenção, apoio e educação; e denunciar todas as formas de omissão, transgressão e violação dos direitos humanos, civis, políticos e sociais, resultantes de discriminação aos portadores (as) do HIV/Aids.

Os serviços oferecidos pelas organizações integrantes do Fórum abrangem a prevenção das Doenças Sexualmente Transmissíveis, distribuição gratuita de preservativos, assistência jurídica, assistência social, assistência psicológica, Casa de apoio, aconselhamento, palestras em escolas, empresas, faculdades, grupo de adesão aos medicamentos de HIV, cooperativa de sustentabilidade, distribuição de kits para usuários de drogas entre outras ações.

O Fórum é composto por organizações declaradamente relacionadas à causa da Aids e por aquelas que apóiam o movimento, acompanhando o debate sobre a natureza dessas organizações. Na tabela a seguir estão as organizações que se auto-denominam ONGs/Aids: 


\begin{tabular}{|c|c|c|}
\hline Organização & PÚBLICO ALVO & Localização \\
\hline $\begin{array}{l}\text { GRUPO AAVE - Aids: } \\
\text { Apoio, Vida e Esperança }\end{array}$ & $\begin{array}{l}\text { Pessoas vivendo com HIV/ } \\
\text { Aids em Goiânia }\end{array}$ & $\begin{array}{l}\text { Rua Iporá, n¹70, Q.19, Lt. } \\
15 \text { Bairro Nossa Senhora } \\
\text { de Fátima, Goiânia - Go. }\end{array}$ \\
\hline AMOR E VIDA & $\begin{array}{l}\text { Trabalhadores do sexo e } \\
\text { pessoas vivendo com HIV } \\
\text { em Ceres }\end{array}$ & $\begin{array}{l}\text { Pça. São Pio X, nº. } 76 \text {, } \\
\text { Centro, Ceres-Go. }\end{array}$ \\
\hline $\begin{array}{l}\text { CADA - Centro de Apoio } \\
\text { ao Doente de Aids }\end{array}$ & $\begin{array}{l}\text { Pessoas vivendo com Aids } \\
\text { em Aparecida de Goiânia }\end{array}$ & $\begin{array}{l}\text { Avenida Anápolis, qd. } \\
\text { 42A, Vila Brasília. Apare- } \\
\text { cida de Goiânia - Go }\end{array}$ \\
\hline GRUPO PELA VIDDA/Go & $\begin{array}{l}\text { Pessoas vivendo com HIV } \\
\text { em Goiânia }\end{array}$ & $\begin{array}{l}\text { Rua } 24, n^{\circ} \cdot 224, \text { Centro - } \\
\text { Goiânia Go. }\end{array}$ \\
\hline $\begin{array}{l}\text { GASI - Grupo de Apoio e } \\
\text { Solidariedade Itumbiarense }\end{array}$ & $\begin{array}{l}\text { Pessoas vivendo com HIV } \\
\text { em Itumbiara }\end{array}$ & Itumbiara - Go \\
\hline $\begin{array}{l}\text { IASSGO - Instituto Social } \\
\text { de Saúde do Estado de } \\
\text { Goiás }\end{array}$ & $\begin{array}{l}\text { Assistência às pessoas vi- } \\
\text { vendo com Aids, casa de } \\
\text { apoio }\end{array}$ & $\begin{array}{l}\text { Rua 109, N. }{ }^{\circ} \text { 122, Qd. F-32 } \\
\text { Lt. 16, Setor Sul Coiânia - } \\
\text { Go }\end{array}$ \\
\hline SOCIEDADE OASIS & $\begin{array}{l}\text { Pessoas vivendo com HIV } \\
\text { em Anápolis }\end{array}$ & $\begin{array}{l}\text { Avenida Presidente Var- } \\
\text { gas, sem número, Vila Goi- } \\
\text { ás, Anápolis - Go. }\end{array}$ \\
\hline $\begin{array}{l}\text { LAÇOS - Associação Soli- } \\
\text { dária ao HDT }\end{array}$ & $\begin{array}{l}\text { Pacientes, Colaboradores, } \\
\text { Funcionários do Hospital } \\
\text { de Doenças Tropicais - } \\
\text { HDT - Goiânia - Go }\end{array}$ & $\begin{array}{l}\text { Rua C } 130 \text { qd. 250, lote } 03 \\
\text { casa } 02 \text { Jardim América - } \\
\text { Goiânia - Go. }\end{array}$ \\
\hline $\begin{array}{l}\text { RENASCER - casa de } \\
\text { Apoio ao portador de HIV/ } \\
\text { Aids }\end{array}$ & $\begin{array}{l}\text { Assistência a pessoas vi- } \\
\text { vendo com AIDS, Casa de } \\
\text { Apoio }\end{array}$ & $\begin{array}{l}\text { Rua L-03, Qd. 01, Lt. 06, } \\
\text { Conjunto Vila Isabel, Goi- } \\
\text { ânia-Go. }\end{array}$ \\
\hline
\end{tabular}

Fonte: Fórum de ONGs/Aids do Estado de Goiás, 2007

Na perspectiva da representatividade, o Fórum de Ongs/Aids do Estado de Goiás é constituído por um membro eleito de cada organização e pelo presidente eleito pelos representantes de cada organização, compondo o coletivo que se articula e se encontra em reuniões periódicas. Obviamente, nem todas as organizações que o compreende participam ativamente do Fórum, refletindo algumas dinâmicas: freqüentes atritos entre pessoas e organizações, ocasionados em grande parte pela várias identidades organizativas que se confrontam, pelo conflito entre militância e interesses políticos, entre ativismo e captação de recursos, via projetos.

Mas, o que representa esse Fórum? Qual o seu espaço de atuação? É interessante apontar que, ao mesmo tempo, trata-se de uma articulação estadual de organizações de Aids e de uma organização formal sem fins 
lucrativos. A formalidade, do ponto de vista jurisdicional, é extremamente favorável aos interesses do Fórum, pois possibilita e facilita fomentos de projetos, por parte das secretarias de saúde, da iniciativa privada, de organizações internacionais e de organizações religiosas. Assim, ao representar interesses de um grupo comum, pessoas que convivem com HIV/Aids, o Fórum adquire força política, paralela e como parte das políticas Estaduais e Municipais de saúde, ora pressionando o setor governamental, ora em parceria.

Um outro ponto de destaque são as constantes disputas entre as organizações que integram o Fórum. A quantidade de entidades sem fins lucrativos direcionadas à Aids é superior às fontes de fomento, aumentando a concorrência entre elas. Assim, as organizações que funcionam como casas de apoio, centros de prevenção, de captação de recursos, de aconselhamento entre outras, tem que contar com a ajuda pessoalizada, de famílias, de trabalho voluntário, para dar continuidade aos trabalhos das organizações que não conseguem financiamentos via projetos.

A dificuldade de manutenção da sustentabilidade organizacional faz com que parte das ONGs/Aids encerrem suas atividades ou trabalhem sem recursos. Assim, a parceria entre as organizações é positiva, devido à força política do coletivo organizacional. Assim sendo, a articulação das organizações de Aids no Estado de Goiás é benéfica aos interesses das próprias organizações, da sociedade, das pessoas que vivem com HIV/Aids e ao governo [que lhes atribuem responsabilidades sociais, como extensão de suas atividades]. A articulação política contribui para o aumento do poder e para a construção de uma imagem organizativa positiva.

Mesmo diante da complexa rede organizativa em que se transformaram as ONGs/Aids, essas organizações apresentam dificuldades de atuação e manutenção de suas atividades. Constantemente interpretadas como organizações de Aids, são alvos de preconceitos, advindo da doença e aliado a imagem negativa que adquiriram as ONGs, em sua trajetória histórica.

\section{Considerações finais}

A Aids, desde seu surgimento, ressignificou as relações entre alguns tipos de movimentos e organizações sociais. O impacto ocasionado pelo aumento e distribuição desta doença no Brasil refletiu na construção de organizações, em sua maioria voluntárias, relacionadas à causa HIV/Aids. Paralelo 
a esse processo, um número muito maior de pessoas contribuiu para o acirramento do preconceito e exclusão.

Aliado ao drama da [re]inclusão vivido pelo portador está a densa rede política de organizações, governamentais e não-governamentais, dividindo papéis, interesses e ações. As políticas públicas de saúde direcionadas à Aids, oficialmente, são responsabilidades do setor governamental, porém, a criação, a atuação e as pressões de organizações foi e ainda são responsáveis por grande parte da efetivação de tais políticas. Assim, no caso específico dessa doença, a responsabilidade política se constrói de forma conjunta, uma vez que muitos gestores e militantes dessas organizações são portadores do vírus HIV, trazendo consigo um viés ativista e militante à causa.

Portanto, diante da construção de uma gestão de saúde mais participativa, entre o governamental e o não-governamental, impulsionada pelo poder representativo das ONGs/Aids, está a contradição das ações e a transferência de responsabilidades políticas, no qual constrói-se cotidianamente a ação política do próprio portador, (re)significando e redimensionando a doença, transformando-a em uma sorologia política, no qual diminui as distância entre o espaço público e o privado, entre a rigidez dessas esferas, no combate à epidemia. Para além de dados oficiais, a experiência do HIV/Aids em Goiás, assim como em todo território nacional, é acompanhada por estigmas e discriminação, formas de expressão da exclusão social vivida pelo portador, transformando-a em um paradigma contemporâneo do drama.

1 Atualmente, a grande parte das organizações que constituem o Movimento Nacional de Luta contra a Aids estão articuladas em Fóruns estaduais. Esses Fóruns são espaços de representação de ONGs e movimentos sociais com atuação em HIV/Aids no âmbito de um estado. Uma das características desses espaços são as trocas de experiências entre as diferentes organizações da sociedade civil, visando o fortalecimento das mesmas e deliberações conjuntas sobre assuntos e estratégias que envolvem o enfrentamento da epidemia de Aids. Os Fóruns nasceram a partir de 1996, quando foi criado o Fórum de ONG/Aids do Estado de São Paulo. Atualmente, existem 27 Fóruns de ONG/Aids no país.

2 Optamos neste momento em utilizar a sigla Aids referindo-se à doença de modo geral: ao doente de Aids, ao portador, ao HIV, à soropositividade. Entretanto, além da utilização desta sigla, optamos em alguns momentos ao uso das expressões HIV/Aids ou somente HIV, apontando para as diferenças entre estes termos, relacionados aos estágios de manifestação da doença. 


\section{Referências}

Associação Brasileira de Organizações Não Governamentais - Abong. Um novo Marco Legal para as ONGs no Brasil: fortalecendo a cidadania e a participação democrática. São Paulo: Abong, 2007, disponível em www.abong.org.br.

Fórum de ONGs/Aids do Estado de Goiás - FOAEG. O que é o Fórum de ONGs/Aids do Estado de Goiás. Informativo. FOAEG, Goiânia, 2007.

GOHN, Maria da Glória. Os Sem-Terra, ONGs e Cidadania. 3 ed. São Paulo: Cortez, 2003.

MANFREDI, Silvia Maria. Educação profissional no Brasil. São Paulo: Cortez, 2002.

MOURA, Alexandrina S. Non-governamental Organizations in Brazil: from opposition to partnership. XIII International Congress of Latin Amarican Studies Association. Atlanta, USA, 1994.

RAMOS, Silvia. "O Papel das ONGs na Construção de Políticas de Saúde. A Aids, Saúde da Mulher e Saúde Mental”. In: Revista de Ciência e Saúde Coletiva, Rio de Janeiro, 2004.

ROCHE, Crhis. Avaliação de Impacto dos Trabalhos das ONGs: aprendendo a valorizar as mudanças/ Crhis Roche [edição adaptada para o Brasil ABONG; tradução: Tisel Tradução e Interpretação Simultânea escrita]. 2 ed. São Paulo: Cortez: ABONG; Oxford, Inglaterra: Oxfam, 2002.

SILVA, Criscina Luci Câmara. "ONGs/Aids, intervenções sociais e novos laços de solidariedade social”. In: Cadernos de Saúde Pública. Rio de Janeiro: 1998. Pgs. 129-139.

Genésio Aarim Limo - Mestre em Geografia pela Universidade Federal de Goiás

Antônio Carlos Pinheiro - Professor Dr. da Universidade Federal de São Paulo

Recebido para puplicação em abril de 2008

Aceito para publicação em agosto de 2008 
